Research Article

\title{
Research on Photovoltaic Grid-Connected Control Strategy Based on Active Disturbance Rejection of Adaptive Extended State Observer
}

\author{
Dejun Liu ${ }^{(D)},{ }^{1}$ Jinfei Xu $\mathbb{C}^{2},{ }^{2}$ Ruonan Xue $\mathbb{D}^{2},{ }^{2}$ Chao Song $\mathbb{D}^{2},{ }^{2}$ and Zhenxiong Zhou $\mathbb{D}^{2}$ \\ ${ }^{1}$ Engineering Training Center, Beihua University, Jilin, China \\ ${ }^{2}$ College of Electrical and Information Engineering, Beihua University, Jilin, China
}

Correspondence should be addressed to Zhenxiong Zhou; 742884852@qq.com

Received 29 June 2021; Revised 5 September 2021; Accepted 7 September 2021; Published 28 September 2021

Academic Editor: DONG LI

Copyright (c) 2021 Dejun Liu et al. This is an open access article distributed under the Creative Commons Attribution License, which permits unrestricted use, distribution, and reproduction in any medium, provided the original work is properly cited.

In the photovoltaic inverter grid-connected power generation system, the output power of photovoltaic panels is affected by illumination and temperature. The change of output power of photovoltaic panels will lead to the fluctuation of DC bus voltage. If the control is improper, it will directly affect the regular operation of the system. In order to improve the performance of the gridconnected inverter system, an active disturbance rejection control method based on adaptive extended state observer (ESO) is proposed. Firstly, a feedforward PI current inner loop controller is designed, which simplifies the structure of the control system and improves the tracking performance of the current. Then, the DC bus voltage outer loop ADRC is designed, and a conversion method that ignores the essential difference between nonlinear/time-varying and time-varying/linear is proposed. Through the conversion of time-invariant nonlinear system and time-varying linear system, the stability of the extended state observer is proved by the Routh criterion. Secondly, to solve the problem of mutual restriction between the stability and observation accuracy of the extended state observer, an adaptive function online automatic tuning ESO parameter method is proposed. Finally, the simulation results show that the proposed method has better dynamic and static performance, and the grid-connected voltage and current harmonics are small, which proves the correctness and effectiveness of the proposed method.

\section{Introduction}

Photovoltaic power generation has the characteristics of environmental protection and efficiency, which is widely used in the fields of electric power, agriculture, modern architecture, and so on [1]. It has become a research hotspot in the field of distributed generation of renewable energy. The grid-connected inverter is the essential equipment to connect photovoltaic array with power grid [2-4].

Since the output power of photovoltaic panels is affected by illumination and temperature [5], the DC-side bus voltage fluctuates, and improper control will directly affect the normal operation of the system. The existing technologies and methods to improve the stability of photovoltaic inverter grid-connected power generation system are mainly studied from three aspects: circuit structure, filter circuit, and control strategy. It is easy to induce resonance by using the filtering method, and it is easy to be affected by power grid impedance. The use of circuit structure leads to complex circuit structure; by improving the control strategy, the method becomes convenient, flexible, and low cost. The control strategy is usually the DC bus voltage control algorithm, controlled by the inverter. In the two-stage threephase photovoltaic grid-connected system, the former stage is the maximum power point tracking control, and the latter stage is the grid-connected inverter control. The grid-connected inverter control is generally the bus voltage for the outer ring and the current loop for the inner ring structure. The inner current loop can be regulated by PI and PR $[6,7]$.

In order to improve the performance of bus voltage control, scholars put forward sliding mode control [8], model predictive control $[9,10]$, adaptive backstepping 
control [2, 11], two-degree-of-freedom control [12], feedback linearization control [13, 14], feedforward decoupling control $[15,16]$, etc. These methods have achieved good results, but they do not consider the external disturbance problem and rely on the mathematical model of the system. Reference [17] adopts an adaptive fuzzy approximation strategy to control grid-connected inverter, but its learning algorithm relies on data information. Reference [18] introduces fuzzy control based on deadbeat grid-connected control, but the determination of fuzzy rules requires experience. In reference [19], particle swarm optimization (PSO) is used to optimize the grid connection design, but the local optimization performance is poor. In reference [20], the cascade control strategy of a fractional-order PID photovoltaic grid-connected system is adopted, but its parameter tuning is difficult.

The core of active disturbance rejection control (ADRC) is that the uncertain factors acting on the controlled object are regarded as "unknown disturbance," and it is observed and compensated with the input and output data of the object. It breaks through the limitations of "the absolute invariance principle" and "the internal model principle" [21-23].

In recent years, the theory and application of active disturbance rejection control (ADRC) have attracted the attention of scholars. They have been successfully applied to chemical, aerospace, electromechanical, power systems, and other systems. The nonlinear active disturbance rejection control of the photovoltaic energy storage bidirectional DCDC converter is proposed [24]. In [25], the proportional differential link is introduced into the linear extended state observer to improve the disturbance rejection of the system. In reference [26], to improve the performance of a threephase current controlled voltage source inverter, LADRCbased active damping control was proposed. In [27], a method to control the bus voltage of wind power inverter using improved second-order LADRC was put forward. Although these methods improve the disturbance rejection of the system, there are still some problems, such as chattering in steady state, complex stability analysis, and mutual restriction between stability and accuracy of extended state observer.

In this paper, a current inner loop feedforward PI controller is designed for the two-stage photovoltaic grid-connected inverter control system to improve the current tracking performance. An active disturbance rejection control strategy based on adaptive ESO is proposed to improve the disturbance rejection of the voltage outer loop. The design uses an adaptive function to automatically adjust the parameters of ESO online to achieve the effect of large error and small gain and small error and large gain. The method improves the stability and observation accuracy of ESO and solves the contradiction between the stability and observation accuracy of nonlinear ESO. On the other hand, aiming at the difficulty of nonlinear ESO stability analysis, a method of transforming the time-invariant nonlinear system into the time-varying linear system is proposed. It is more convenient for stability analysis. Finally, simulation experiment results show that the proposed method is effective and feasible.

\section{Mathematical Model of Three-Phase Photovoltaic Grid-Connected Inverter}

The two-stage three-phase photovoltaic grid-connected system is composed of solar photovoltaic cells, DC/DC converter circuit, and DC/AC inverter circuit. The front stage uses a boost circuit to track the maximum power point of the solar photovoltaic array, and the backstage uses a three-phase full-bridge inverter circuit to complete the gridconnected inverter from DC to AC. Each bridge arm consists of a power switch tube and a diode. The main circuit structure of the system is shown in Figure 1.

$C$ is bus capacitance in the figure; $S_{i j}(i=a, b, c, j=1,2)$ are switching tubes; $u_{a}, u_{b}$, and $u_{c}$ are output voltages of the inverter; $i_{a}, i_{b}$, and $i_{c}$ are output currents of the inverter; $e_{a}$, $e_{b}$, and $e_{c}$ are network voltages; and $i_{0}$ is the first-stage output current.

According to Kirchhoff voltage law (KVL), the dynamic voltage equation of PV grid-connected inverter is expressed as

$$
\left[\begin{array}{l}
\frac{d i_{a}}{d t} \\
\frac{d i_{b}}{d t} \\
\frac{d i_{c}}{d t}
\end{array}\right]=\frac{1}{L}\left[\begin{array}{ccc}
-R & 0 & 0 \\
0 & -R & 0 \\
0 & 0 & -R
\end{array}\right]\left[\begin{array}{l}
i_{a} \\
i_{b} \\
i_{c}
\end{array}\right]+\left[\begin{array}{l}
u_{a}-e_{a} \\
u_{b}-e_{b} \\
u_{c}-e_{c}
\end{array}\right] .
$$

When the three-phase grid voltage is stable and symmetrical, the inverter side currents $i_{a}, i_{b}$, and $i_{c}$, grid voltages $e_{a}, e_{b}$, and $e_{c}$, and inverter output voltages $u_{a}, u_{b}$, and $u_{c}$ are selected as state variables. Through $3 / 2$ transformation, the mathematical model of grid-connected inverter in $\alpha \beta$ stationary coordinate system is obtained as follows:

$$
L \frac{d}{\mathrm{~d} t}\left[\begin{array}{l}
i_{\alpha} \\
i_{\beta}
\end{array}\right]+\left[\begin{array}{ll}
R & 0 \\
0 & R
\end{array}\right]\left[\begin{array}{l}
i_{\alpha} \\
i_{\beta}
\end{array}\right]=\left[\begin{array}{l}
e_{\alpha} \\
e_{\beta}
\end{array}\right]-\left[\begin{array}{l}
u_{\alpha} \\
u_{\beta}
\end{array}\right],
$$

where $u_{\alpha}, u_{\beta}$ and $i_{\alpha}, i_{\beta}$ are the components of inverter output voltage and current on the $\alpha \beta$ axis and $e_{\alpha}$ and $e_{\beta}$ are the components of grid voltage on the $\alpha \beta$ axis.

Through the $2 s / 2 r$ rotation transformation, the mathematical model of the AC side of the grid-connected inverter in the $d q$ synchronous rotating coordinate system is

$$
\left\{\begin{array}{l}
u_{d}=R i_{d}+L \frac{\mathrm{d} i_{d}}{\mathrm{~d} t}-\omega L i_{q}+e_{d}, \\
u_{q}=R i_{q}+L \frac{\mathrm{d} i_{q}}{\mathrm{~d} t}+\omega L i_{d}+e_{q},
\end{array}\right.
$$

where $R$ and $L$ represent the equivalent resistance and inductance of the grid and $\omega$ is the angular frequency of the AC network.

According to equation (3), let the state equation of the AC side of the grid-connected inverter be 


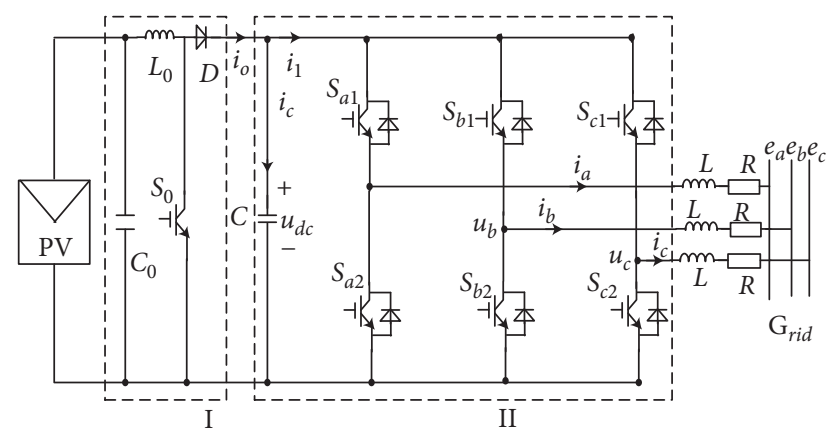

Figure 1: Two-stage PV grid-connected inverter topology.

$$
\left\{\begin{array}{l}
\dot{x}_{1}=\frac{1}{L}\left(u_{d}-R x_{1}+\omega L x_{2}-e_{d}\right), \\
\dot{x}_{2}=\frac{1}{L}\left(u_{q}-R x_{2}-\omega L x_{1}-e_{q}\right) .
\end{array}\right.
$$

\section{Design of Controller}

The control system adopts double closed-loop control, which is primarily composed of internal and external loop controllers, phase-locked loop (PLL), voltage (current) transform $(\mathrm{abc} / \mathrm{d} q)$, static/rotary transform $(\mathrm{d} q / \alpha \beta)$, and pulse generator. The outer loop adopts the active disturbance rejection controller (ADRC), and the inner loop adopts the PI controller with feedforward compensation. The control structure diagram is shown in Figure 2.

\subsection{Design of Inner Loop Controller. From equation (3),}

$$
\left\{\begin{array}{l}
L \frac{\mathrm{d} i_{d}}{\mathrm{~d} t}=u_{d}-R i_{d}+\omega L i_{q}-e_{d} \\
L \frac{\mathrm{d} i_{q}}{\mathrm{~d} t}=u_{q}-R i_{q}-\omega L i_{d}-e_{q}
\end{array}\right.
$$

For the controlled object shown in equation (5), if the grid current is used as the feedback of the current loop and the feedforward PI controller is adopted, the control equation is obtained:

$$
\left\{\begin{array}{l}
u_{d}^{*}=k_{p}\left(i_{d}^{*}-i_{d}\right)+k_{i} \frac{i_{d}^{*}-i_{d}}{s}+e_{d}-\omega L i_{d}+R i_{d}, \\
u_{q}^{*}=k_{p}\left(i_{q}^{*}-i_{q}\right)+k_{i} \frac{i_{q}^{*}-i_{q}}{s}+e_{q}+\omega L i_{q}+R i_{q}
\end{array}\right.
$$

where $k_{p}$ and $k_{i}$ are proportional and integral gains of current inner loop PI regulator, respectively, and $u_{d}^{*}$ and $u_{q}^{*}$ are the components of the modulation voltage of the inverter on the $\mathrm{d} q$ axis.

It is generally considered that $u_{d}^{*}$ and $u_{q}^{*}$ are approximately equal to $u_{d}$ and $u_{q}$; therefore, by combining equations (5) and (6),

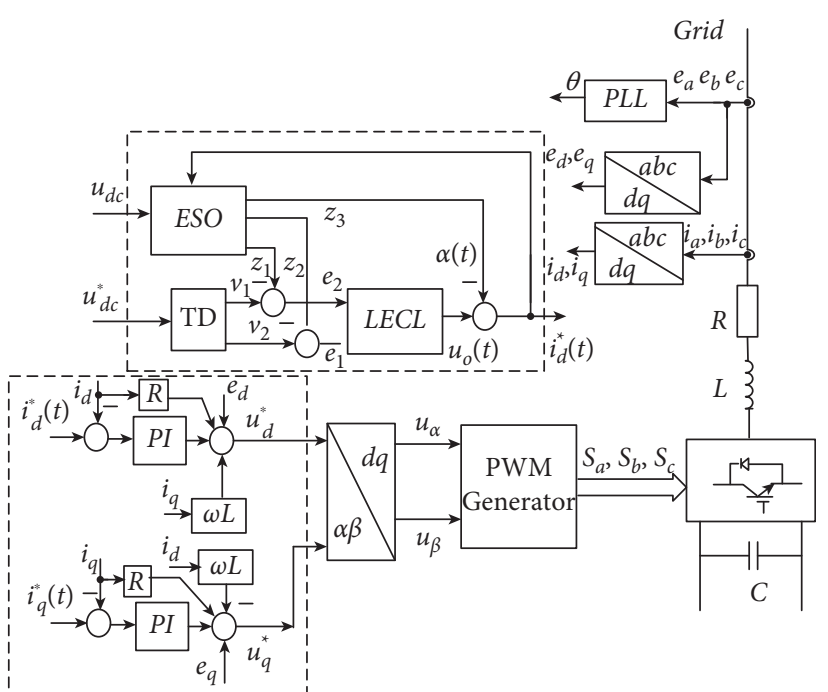

FIGURE 2: Block diagram of control system structure.

$$
\left(L s+\frac{k_{i}}{s}+k_{p}\right) i_{d}(s)=\left(k_{p}+\frac{k_{i}}{s}\right) i_{d}^{*}(s) .
$$

The closed-loop transfer function is presented as

$$
G_{i}(s)=\frac{i_{d}(s)}{i_{d}^{*}(s)}=\frac{k_{p}+k_{i} / s}{L s+k_{p}+k_{i} / s}=\frac{k_{p} s+k_{i}}{L s^{2}+k_{p} s+k_{i}} \text {. }
$$

3.2. Design of Outer Loop Controller. The outer loop adopts the active disturbance rejection controller (ADRC), and the control block diagram is shown in Figure 3. TD is the differential tracker, LECL is the linear error control law, and ESO is the extended state observer.

From Figure 3, $G_{t}(s)$ is the transfer function of the power electronic converter, and its expression is

$$
G_{t}(s)=\frac{u_{\mathrm{dc}}(s)}{i_{d}(s)}=\frac{k_{s}}{T_{s} s+1} .
$$

The generalized object transfer function of ADRC is

$$
G_{p}(s)=\frac{k_{p} s+k_{i}}{L s^{2}+k_{p} s+k_{i}} \frac{k_{s}}{T_{s} s+1} .
$$

Because $T_{s}$ is small, according to the engineering design criterion [28], equation (10) is approximated as a secondorder system with uncertainties, which can be constructed as shown in the following equation:

$$
G_{p}(s) \approx \frac{k}{s^{2}+a_{1} s+a_{2}}+\Delta(s) .
$$

The differential equation of the system in the form of equation (11) can be expressed as

$$
\ddot{y}=f(y, \dot{y}, \xi)+\mathrm{bu}=-a_{1} \dot{y}-a_{2} y+\xi+\mathrm{bu},
$$

where $y$ is the system output; $\xi$ is the external disturbance; $u$ is the system input; $a_{1}$ and $a_{2}$ are the controlled system parameters; $b$ is the control gain; and $f(y, \dot{y}, \xi)$ is the 


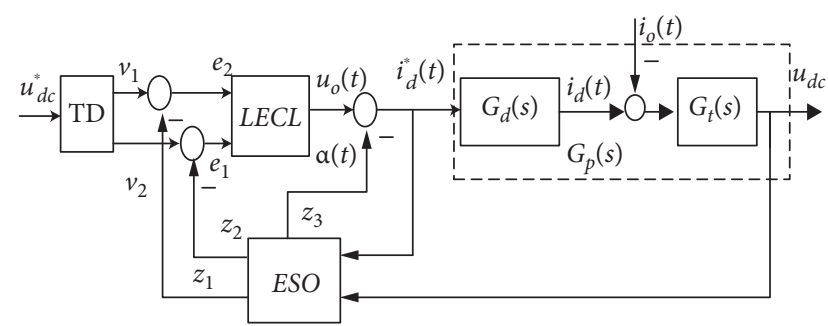

FIgURE 3: Block diagram of double closed-loop control system.

synthesis of the internal and external disturbance. Most systems $\left(a_{1}, a_{2}\right.$, and $\left.b\right)$ are difficult to obtain accurately; let the second-order system be expressed as

$$
\ddot{y}=d+b_{0} u,
$$

where $d=f(y, \dot{y}, \xi)+\left(b-b_{0}\right) u$ is the total disturbance to be observed and $b_{0}$ is known.

Let $x_{1}=y, x_{2}=\dot{y}, x_{3}=f(y, \dot{y}, \xi, t)=-a_{1} \dot{y}-a_{2} y+$ $\xi_{+}\left(b-b_{0}\right) u$, and the equation of state can be obtained as follows:

$$
\left\{\begin{array}{l}
\dot{x}_{1}=x_{2} \\
\dot{x}_{2}=x_{3}+b_{0} u \\
\dot{x}_{3}=\dot{f}(y, \dot{y}, \xi, t)=w(t)
\end{array}\right.
$$

The following nonlinear tension state observer is designed for system (14), and its differential equation is

$$
\left\{\begin{array}{l}
e=z_{1}-y \\
\dot{z}_{1}=z_{2}-\beta_{01} e \\
\dot{z}_{2}=z_{3}-\beta_{02} \mathrm{fal}\left(e, \alpha_{1}\right)+b_{0} u, \\
\dot{z}_{3}=-\beta_{03} \mathrm{fal}\left(e, \alpha_{2}\right),
\end{array}\right.
$$

where $\beta_{01}, \beta_{02}$, and $\beta_{03}$ are the gains of nonlinear tensor state observer and $\mathrm{fal}(e, \alpha)=|e|^{\alpha} \operatorname{sign}(e)$.

The nonlinear tensor state observer is asymptotically stable by adequately selecting $\beta_{01}, \beta_{02}$, and $\beta_{03}$. That is to realize the real-time tracking of $x_{1}, x_{2}$ and $x_{3}$, namely, $z_{1} \longrightarrow x_{1}$, $z_{2} \longrightarrow x_{2}$, and $z_{3} \longrightarrow x_{3}$. Let

$$
u=\frac{-z_{3}+u_{0}}{b_{0}}
$$

Then, the second-order system can be transformed into an integral series type in the following form:

$$
\ddot{y}=d+b_{0} u=f(y, \dot{y}, \xi)+\left(b-b_{0}\right) u+b_{0} u \approx z_{3}+b_{0} u=u_{0} .
$$

The following control law is adopted:

$$
u_{0}=k_{p}\left(r-z_{1}\right)+k_{d}\left(\dot{r}-z_{2}\right)+\frac{k_{i}}{s}\left(r-z_{1}\right) \text {, }
$$

where $r$ is the reference signal. Let $\dot{r}=0$, and because $z_{1} \longrightarrow y$ and $z_{2} \longrightarrow \dot{y}$, the closed-loop transfer function of the system is

$$
\begin{aligned}
\ddot{y} & =k_{p}\left(r-z_{1}\right)+k_{d}\left(\dot{r}-z_{2}\right)+\int k_{i}\left(r-z_{1}\right) \mathrm{d} t \\
& =k_{1}(r-y)-k_{2} \dot{y}+\int k_{i}(r-y) \mathrm{d} t, \\
\frac{y(s)}{r(s)} & =\frac{k_{d} s^{2}+k_{p} s+k_{i}}{s^{3}+k_{d} s^{2}+k_{p} s+k_{i}},
\end{aligned}
$$

$\varphi_{\text {pid }}(s)=s^{3}+k_{d} s^{2}+k_{p} s+k_{i}$

It can be concluded from equation (21) that if the output variables of nonlinear tension state observer are asymptotically stable, the stability of the system depends on $k_{p}, k_{i}$, and $k_{d}$.

3.3. Estimation Error Analysis of ESO. Let $e_{1}=z_{1}-x_{1}$, $e_{2}=z_{2}-x_{2}, e_{3}=z_{3}-x_{3}$, and equation (14) can be written as

$$
\left\{\begin{array}{l}
\dot{z}_{1}-\dot{x}_{1} \mid=z_{2}-\beta_{01}\left(z_{1}-x_{1}\right)-x_{2}=\dot{e}_{1}=e_{2}-\beta_{01} e_{1} \\
\dot{z}_{2}-\dot{x}_{2} \mid=z_{3}-\beta_{02} \mathrm{fal}\left(e_{1}\right)+b_{0} u-x_{3}-b_{0} u=\dot{e}_{2}=e_{3}-\beta_{02} \mathrm{fal}\left(e_{1}\right) \\
\dot{z}_{3}-\dot{x}_{3} \mid=-w(t)-\beta_{03} \mathrm{fal}\left(e_{1}\right)=\dot{e}_{3}=-w(t)-\beta_{03} \mathrm{fal}\left(e_{1}\right)
\end{array}\right.
$$

where fal $(\cdot)$ is a smooth and continuous function, which can be regarded as a linear function in any small neighborhood of its independent variable. It is considered that fal (.) is composed of countless linear functions. When the observer order is the same as the object order, the principle of ignoring the essential difference between the nonlinear/timevarying and time-varying/linear proposed in this paper is used. The parameter time-invariant differential equation in equation (22) is equivalent to the parameter time-varying differential equation. That is, the constant coefficients $\beta_{01}$, $\beta_{02}$, and $\beta_{03}$ in equation (22) are converted into time-varying coefficients $\beta_{01}(t), \beta_{02}(t)$, and $\beta_{03}(t)$, and fal $\left(e_{1}\right)$ is replaced by $e_{1}$; then, equation (23) can be obtained.

$$
\left\{\begin{array}{l}
\dot{e}_{1}=e_{2}-\beta_{01}(t) e_{1}, \\
\dot{e}_{2}=e_{3}-\beta_{02}(t) e_{1}, \\
\dot{e}_{3}=-w(t)-\beta_{03}(t) e_{1} .
\end{array}\right.
$$

Let $\beta_{01}(t)=\beta_{01}, \beta_{02}(t)=\beta_{02}^{\prime}$, and $\beta_{03}(t)=\beta_{03}^{\prime}$; it can be obtained from equation (23) that

$$
\left\{\begin{array}{l}
\varepsilon_{1}=e_{1}=z_{1}-x_{1}, \\
\varepsilon_{2}=e_{2}-\beta_{01} e_{1}=z_{2}-x_{2}-\beta_{01} e_{1}, \\
\varepsilon_{3}=e_{3}-\beta_{02}^{\prime} e_{1}-\beta_{01} \dot{e}_{1} .
\end{array}\right.
$$

The derivation of equation (24) can be obtained as 


$$
\left\{\begin{array}{l}
\dot{\varepsilon}_{1} \mid=\dot{e}_{1}=z_{2}-\beta_{01}\left(z_{1}-x_{1}\right)-x_{2}=\dot{e}_{1}=e_{2}-\beta_{01} e_{1}=\varepsilon_{2}, \\
\dot{\varepsilon}_{2}=\dot{e}_{2}-\beta_{01} \dot{e}_{1}=\dot{z}_{2}-\dot{x}_{2}-\beta_{01} \dot{e}_{1}=e_{3}-\beta_{02}^{\prime} e_{1}-\beta_{01} \dot{e}_{1}=\varepsilon_{3}, \\
\dot{\varepsilon}_{3} \mid=\dot{e}_{3}-\beta_{02}^{\prime} \dot{e}_{1}-\beta_{01} \ddot{e}_{1}=\dot{e}_{3}-\beta_{02}^{\prime} \dot{e}_{1}-\beta_{01}\left(\dot{e}_{2}-\beta_{01} \dot{e}_{1}\right), \\
\mid=-\beta_{01} \varepsilon_{3}-\beta_{02}^{\prime} \varepsilon_{2}-\beta_{03}^{\prime} \varepsilon_{1}-w(t) .
\end{array}\right.
$$

When $w(t)=0$, the Laplace transform of the third line of the above equation is

$$
s^{3}+\beta_{01} s^{2}+\beta_{02}^{\prime} s+\beta_{03}^{\prime}=0 .
$$

From the Routh stability criterion, it can be concluded that the sufficient and necessary conditions for the stability of the system are that $\beta_{01}, \beta_{02}^{\prime}$, and $\beta_{03}^{\prime}$ are all greater than zero. Furthermore, under the condition $\beta_{01} \bullet \beta_{02}^{\prime}>\beta_{03}^{\prime}$, the zero solutions of the system $e_{1}(t)=0, e_{2}(t)=0$, and $e_{3}(t)=$ 0 are globally asymptotically stable.

When the disturbance $w(t)$ is considered, it is bounded, i.e., $|w(t)| \geq w_{0}$, and the system has a steady-state error. From the final value theorem, the following equation can be obtained:

$$
\begin{aligned}
& \left|e_{1}(t)\right| \leq \frac{w_{0}}{\beta_{03}^{\prime}}, \\
& \left|e_{2}(t)\right| \leq \frac{\beta_{01} w_{0}}{\beta_{03}^{\prime}}, \\
& \left|e_{3}(t)\right| \leq \frac{\beta_{02} w_{0}}{\beta_{03}^{\prime}} .
\end{aligned}
$$

It can be seen that when $\beta_{01}, \beta_{02}^{\prime}$ are smaller and $\beta_{03}^{\prime}$ is larger, the observation errors of state $x_{1}, x_{2}$ and $x_{3}$ are smaller. However, the stability should meet the requirements of $\beta_{01} \bullet \beta_{02}^{\prime}>\beta_{03}^{\prime}$, so the parameter tuning of the observer needs to be comprehensively considered.

3.4. ESO Adaptive Extended State Observer. From the above analysis, it can be obtained that the stability of the extended state observer is directly related to the stability of the system. The larger $\beta_{03}^{\prime}$ is, the shorter the estimation time is and the smaller the steady-state error is. However, if $\beta_{03}^{\prime}$ is too large, the estimated value will not converge. Besides, $\beta_{01}$ and $\beta_{02}^{\prime}$ affect the transition process and stability of state estimation, and too large values can also cause estimation instability. Therefore, this paper adopts the adaptive function tuning method, and the designed parameter tuning function is

$$
\beta_{i}=A+B \cdot e^{\left(-\lambda\left|z_{1}-y\right|\right)},
$$

where $A$ is the minimum base value, $B$ is the dynamic extremum, and $\lambda$ is the attenuation coefficient.

The function has the characteristics of a small function value when the error is significant and an enormous function value when the error is small so that the extended state observer converges quickly and the steady-state error is small. The problem of mutual restriction between observer stability and observation accuracy with constant parameters is avoided.

\section{Simulation Research}

To verify the effectiveness of the grid-connected inverter control algorithm proposed in this paper, the simulation model of the photovoltaic grid-connected inverter is built by using MATLAB/Simulink simulation software. The model is connected to a $35 \mathrm{kV}$ power grid through a DC-DC boost converter, three-phase inverter, and three-phase coupling transformer. The system's main circuit is shown in Figure 1, and the system control structure is shown in Figure 2. For the front stage boost circuit, the "incremental conductance + integral regulator" technology is used to realize the maximum power tracking of the PV cells. The primary parameters of the main circuit are summarized in Table 1.

The parameters of the extended state observer and the linear error control law are shown in Table 2.

Figure 4 shows the setting curves of light intensity and temperature.

To verify the superiority of the control algorithm proposed in this article, the simulation experiments of the voltage loop controller are PID, ADRC with constant parameter $\mathrm{ESO}$, and $\mathrm{ADRC}$ with adaptive $\mathrm{ESO}$, respectively. The inner current loop controller parameters under the three outer loop control modes are as follows: $k_{p}=0.3, k_{i}=30$. Figure 5 shows the DC bus voltage curves under the action of different controllers. Figure 6 shows the response curves of adaptive ESO and ordinary ESO.

From Figure 5, it can be obviously seen that the overshoot of adaptive ESO active disturbance rejection control is small and the response time is short before the disturbance is added. When the disturbance is added, the DC bus voltage fluctuation of adaptive ESO active disturbance rejection control is small and restored quickly to the expected value.

It can be seen from Figure 6 that the adaptive ESO observation has the advantages of smooth observation state, small fluctuation, and fast convergence compared with the constant parameter ESO. The reason why the initial ADRC has small overshoot and fast response is that the differential tracker (TD) effectively arranges the transition process. At the same time, since the adaptive ESO active disturbance rejection control adopts online parameter self-tuning, which effectively realizes the effect of large error and small gain and small error and large gain. Therefore, the state observation is smooth and has fast convergence and good disturbance rejection.

Figure 7 shows the A-phase voltage and current curves of ADRC with adaptive ESO, ADRC with constant parameter ESO, and PID control, respectively. 
TABLE 1: Primary parameters of the main circuit.

\begin{tabular}{lcc}
\hline Parameters & Value & Unit \\
\hline Rated output power & 100 & $\mathrm{~kW}$ \\
Bus capacitance & 100 & $\mu \mathrm{F}$ \\
Open-circuit voltage & 500 & $\mathrm{~V}$ \\
Inductance & 0.25 & $\mathrm{mH}$ \\
Resistance & 0.002 & $\Omega$ \\
Grid frequency & 50 & $\mathrm{~Hz}$ \\
\hline
\end{tabular}

TABle 2: Parameters of the controller.

\begin{tabular}{lc}
\hline Parameters & Value \\
\hline$\beta_{01}$ & 1 \\
$\beta_{02}$ & $20+15 \cdot e^{\left(-30\left|z_{1}-y\right|\right)}$ \\
$\beta_{03}$ & $10+10 \cdot e^{\left(-30\left|z_{1}-y\right|\right)}$ \\
$k_{\mathrm{pu}}$ & 20 \\
$k_{\mathrm{iu}}$ & 800 \\
$k_{\mathrm{du}}$ & 0.1 \\
\hline
\end{tabular}

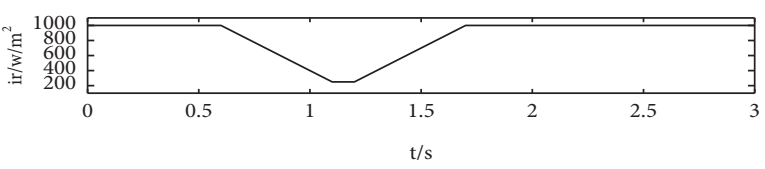

(a)

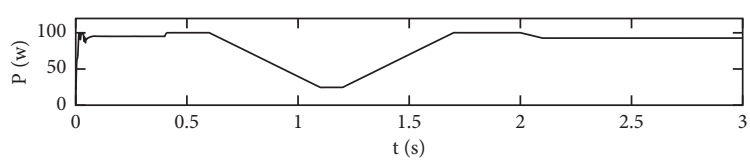

(c)

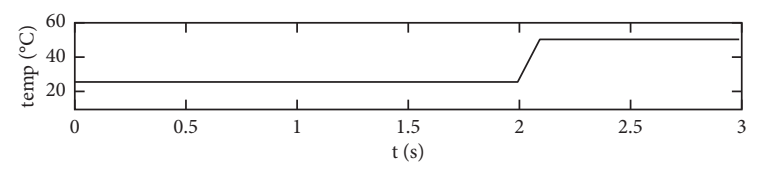

(b)

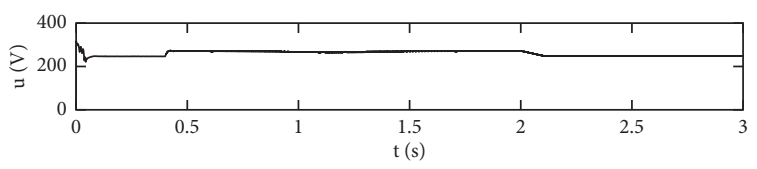

(d)

FIGURE 4: Setting curve of light intensity and temperature change.

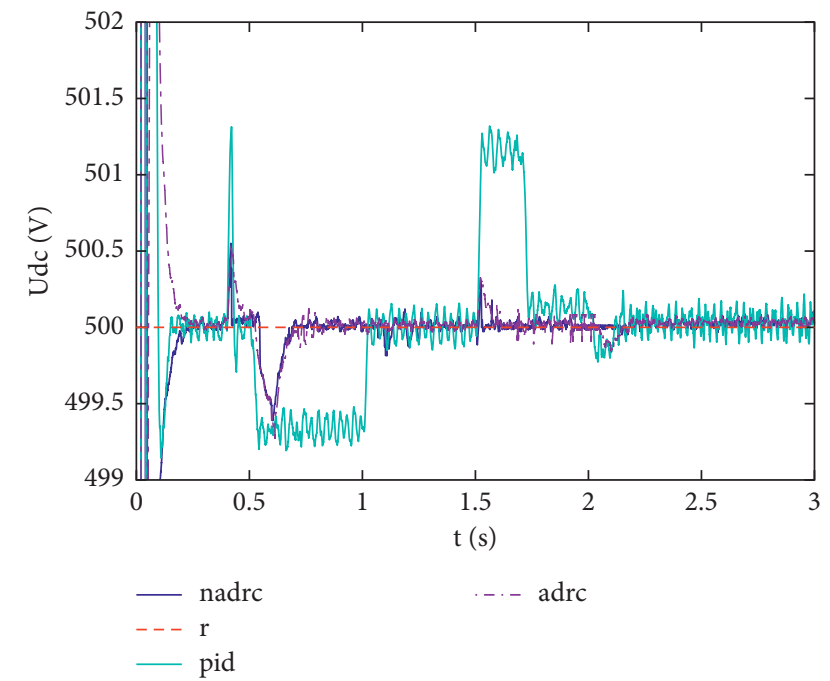

FIgURe 5: Response curves of the DC bus voltage.

It can be seen from Figure 7 that compared with ordinary $\mathrm{ADRC}$, the improved $\mathrm{ADRC}$ has a smaller initial response current fluctuation frequency and faster current regulation speed. It only needs about 1.5 cycles to quickly realize that the output current and voltage of the grid-connected inverter are in phase, indicating that the grid-connected inverter can operate with high power factor. However, the PID control takes a long time to adjust and requires two cycles. The output current of the grid-connected inverter cannot be in phase with the grid voltage quickly, and the output current has burrs and is not smooth.

In order to further compare the control performance, harmonic analysis is carried out on the output A-phase voltage and current of the inverter. Tables 3 and 4 show the harmonic analysis of A-phase voltage and current controlled by ADRC with adaptive ESO, ADRC with constant parameters ESO, and PID.

From Tables 3 and 4, it can be seen that the basic wave amplitude of the output voltage of the grid-connected inverter is $2.792 * 10^{4}$, and the total harmonic content of the voltage is $0.02 \%$. The basic wave amplitude of current is 2.237 , and the overall harmonic content of current is $1.68 \%$. The basic wave amplitude of the output voltage of the conventional active disturbance rejection control grid-connected inverter is $2.789 * 10^{4}$, and the total harmonic content of the voltage is $0.02 \%$. The basic wave amplitude of current is 2.236 , and the overall harmonic content of current is $1.74 \%$. Besides, PI control 


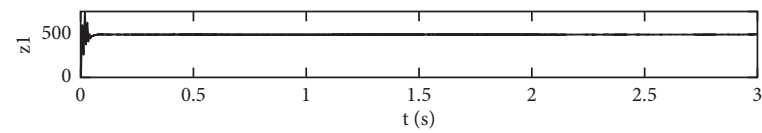

(a)

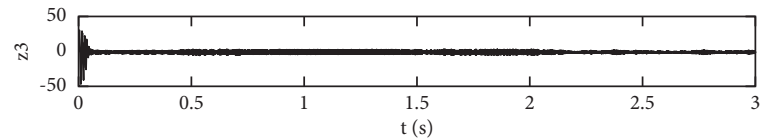

(c)

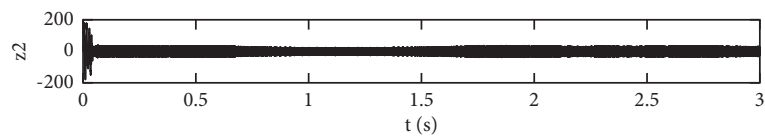

(e)

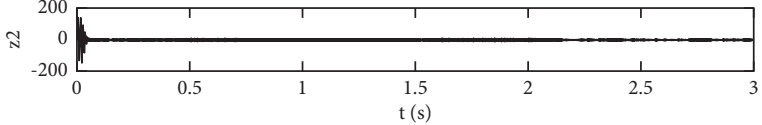

(b)

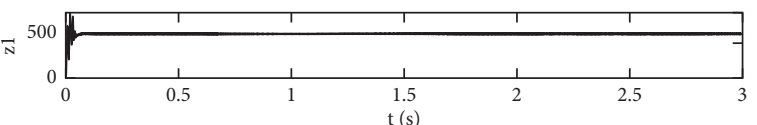

(d)

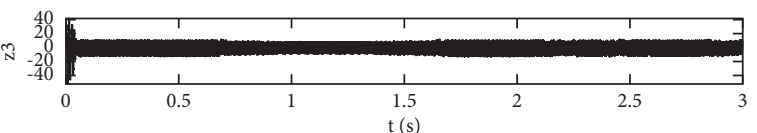

(f)

Figure 6: Response curves of adaptive ESO and ordinary ESO.
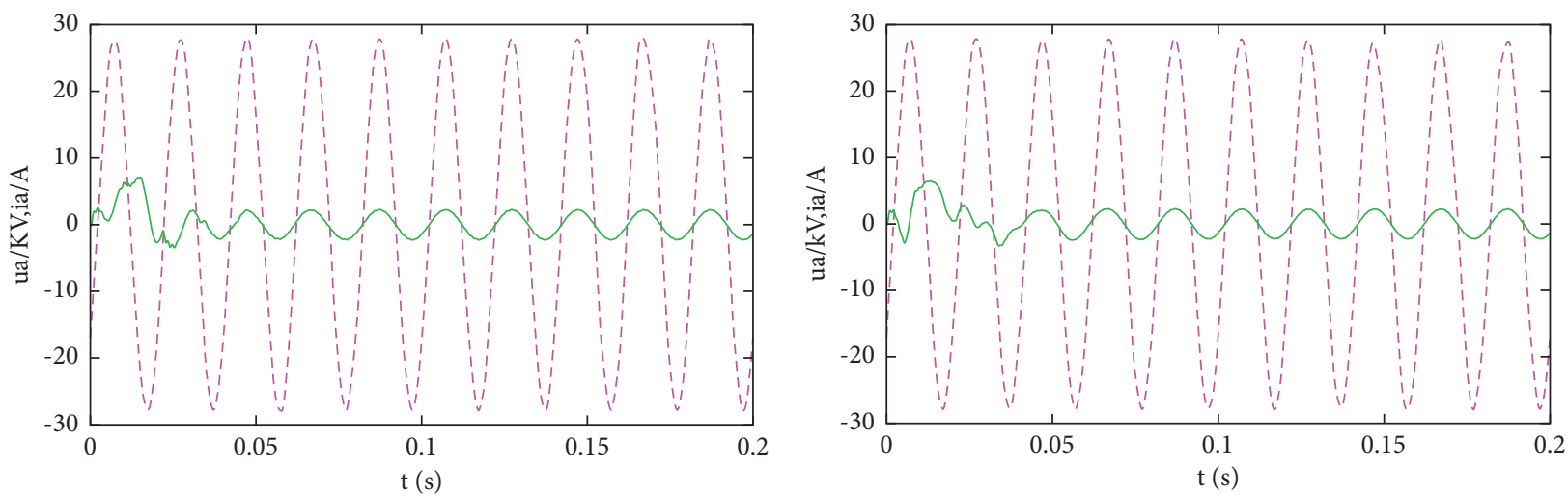

-- - ua

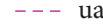

— ia

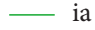

(a)

(b)

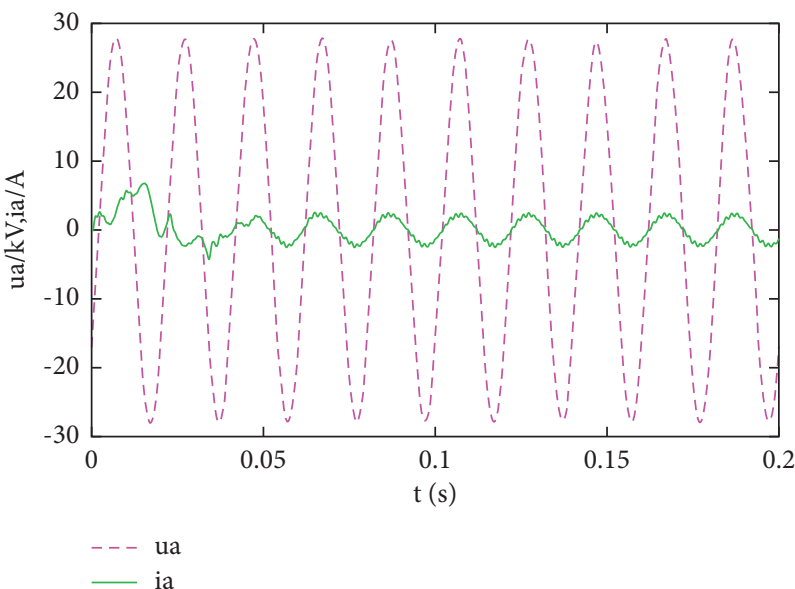

(c)

FIGURE 7: $u_{a}$ and $i_{a}$ response curves. (a) $u_{a}$ and $i_{a}$ response curves of the improved ADRC. (b) $u_{a}$ and $i_{a}$ response curves of the ADRC. (c) $u_{a}$ and $i_{a}$ response curves of the PID control.

grid-connected inverter output voltage fundamental wave amplitude is $2.789 * 10^{4}$, and the overall voltage harmonic content is $0.08 \%$. The basic wave amplitude of current is 2.358 , and the overall harmonic content of current is $9.33 \%$. Therefore, a conclusion can be drawn that the proposed control strategy of grid-connected inverter output current and voltage of the total harmonic content is small, better than the traditional ADRC and PID control. 
TABLE 3: Harmonic analysis comparison of phase A voltage.

\begin{tabular}{lcr}
\hline Controllers & Fundamental $(50 \mathrm{~Hz})$ & THD (total harmonic distortion) $(\%)$ \\
\hline Improved ADRC & $2.792 * 10^{4}$ & 0.02 \\
LADRC & $2.789 * 10^{4}$ & 0.02 \\
PI & $2.789 * 10^{4}$ & 0.08 \\
\hline
\end{tabular}

TABLE 4: Harmonic analysis comparison of phase A current.

\begin{tabular}{lcc}
\hline Controllers & Fundamental $(50 \mathrm{~Hz})$ & THD (total harmonic distortion) $(\%)$ \\
\hline Improved ADRC & 2.237 & 1.68 \\
LADRC & 2.236 & 1.74 \\
PI & 2.358 & 9.33 \\
\hline
\end{tabular}

\section{Conclusions}

This paper considers the influence of uncertain factors such as light intensity and temperature changes and combined with the strong anti-interference ability of active disturbance rejection control. Aimed at the above characteristics, a control method of active disturbance-rejection grid-connected inverter based on adaptive ESO is proposed. In this method, adaptive function online automatic ESO tuning parameters can achieve fast and accurate state observation estimation. The following conclusions are obtained through experiments:

(1) This method equates the time-invariant differential equation to the parameter time-varying differential equation, so that it is convenient to use the Routh stability criterion to analyze the stability of the nonlinear extended states.

(2) The ESO parameter tuning function is designed to realize the online self-tuning of ESO parameters, eliminate the contradiction between the stability of ESO with constant parameters and the observation accuracy, improve the observation performance, and increase the stability of ESO.

(3) Compared with the traditional active disturbance rejection and PID control, this method has better dynamic and static performance and strong robustness under external interference.

\section{Data Availability}

The data used to support the findings of this study are available from the corresponding author upon request.

\section{Conflicts of Interest}

The authors declare that there are no conflicts of interest regarding the publication of this paper.

\section{Acknowledgments}

This study was supported by the Jilin Science and Technology Research Project of Education Department (2015148), Jilin Education Department Project
(JJKH20200042KJ), and Jilin Provincial Development and Reform Commission Project (2019C058-1).

\section{References}

[1] A. Mesloub, A. Ghosh, G. A. Albaqawy, E. Noaime, and B. Alsolami, "Energy and daylighting evaluation of integrated semitransparent photovoltaic windows with internal light shelves in open-office buildings," Advances in Civil Engineering, vol. 2020, Article ID 8867558, 21 pages, 2020.

[2] T. Yang, Z. Cai, and Q. Xun, “Adaptive backstepping-based $\mathrm{H} \$\{\{\backslash$ infty $\}\}$ robust controller for photovoltaic grid- connected inverter," IEEE Access, vol. 8, pp. 17263-17272, 2020.

[3] Y. Yang, K. Zhou, and F. Blaabjerg, "Current harmonics from single-phase grid-connected inverters-examination and suppression," IEEE Journal of Emerging and Selected Topics in Power Electronics, vol. 4, no. 1, pp. 221-233, 2016.

[4] Y. Guan, Y. Wang, Y. Xie, Y. Liang, A. Lin, and X. Wang, "The dual-current control strategy of grid-connected inverter with LCL filter," IEEE Transactions on Power Electronics, vol. 34, no. 6, pp. 5940-5952, 2019.

[5] R. Madurai Elavarasan, A. Ghosh, T. K. Mallick, A. Krishnamurthy, and M. Saravanan, "Investigations on performance enhancement measures of the bidirectional converter in PV-wind interconnected microgrid system," Energies, vol. 12, no. 14, p. 2672, 2019.

[6] C. Wang, X. Li, L. Guo, and Y. W. Li, "A nonlinear-disturbance-observer-based DC-bus voltage control for a hybrid AC/DC microgrid," IEEE Transactions on Power Electronics, vol. 29, no. 11, pp. 6162-6177, 2014.

[7] X. R. Liu, C. Gao, and Z. L. Wang, "DC-bus voltage control for PV grid-connected inverter based on nonlinear disturbance observer," Power System Technology, vol. 44, no. 3, pp. 897-906, 2020.

[8] N. Marcel and N. ClaudiuIonel, "Fractional-order control of grid-connected photovoltaic system based on synergetic and sliding mode controllers," Energies, vol. 14, no. 2, p. 510, 2021.

[9] Y. Shan, J. Hu, and J. M. Guerrero, "A model predictive power control method for PV and energy storage systems with voltage support capability," IEEE Transactions on Smart Grid, vol. 11, no. 2, pp. 1018-1029, 2020.

[10] H. T. Nguyen and J.-W. Jung, "Disturbance-rejection-based model predictive control: flexible-mode design with a modulator for three-phase inverters," IEEE Transactions on Industrial Electronics, vol. 65, no. 4, pp. 2893-2903, 2018. 
[11] A. Ahmad, N. Ullah, N. Ahmed et al., "Robust control of gridtied parallel inverters using nonlinear backstepping approach," IEEE Access, vol. 7, pp. 111982-111992, 2019.

[12] M. Hanif, V. Khadkikar, W. Xiao, and J. L. Kirtley, "Two degrees of freedom active damping technique for \$LCL\$ filterbased grid connected PV systems," IEEE Transactions on Industrial Electronics, vol. 61, no. 6, pp. 2795-2803, 2014.

[13] N.-B. Lai and K.-H. Kim, "Robust control scheme for threephase grid-connected inverters with LCL-filter under unbalanced and distorted grid conditions," IEEE Transactions on Energy Conversion, vol. 33, no. 2, pp. 506-515, 2018.

[14] D. Chen, Y. Qiu, Y. Chen, and Y. He, "Nonlinear PWMcontrolled single-phase boost mode grid-connected photovoltaic inverter with limited storage inductance current," IEEE Transactions on Power Electronics, vol. 32, no. 4, pp. 2717-2727, 2017.

[15] H. Zhang, J. Xian, J. Shi, S. Wu, and Z. Ma, "High performance decoupling current control by linear extended state observer for three-phase grid-connected inverter with an LCL filter," IEEE Access, vol. 8, pp. 13119-13127, 2020.

[16] C.-Y. Liao, W.-S. Lin, Y.-M. Chen, and C.-Y. Chou, "A PV micro-inverter with PV current decoupling strategy," IEEE Transactions on Power Electronics, vol. 32, no. 8, pp. 65446557, 2017.

[17] M. Shadoul, H. Yousef, R. Al Abri, and A. Al-Hinai, "Adaptive fuzzy approximation control of PV grid-connected inverters," Energies, vol. 14, no. 4, p. 942, 2021.

[18] Z. H. Zheng, T. X. Zhang, and J. X. Zhang, "Application of fuzzy control in a photovoltaic grid-connected inverter," Journal of Electrical and Computer Engineering, vol. 2018, Article ID 3806372, 10 pages, 2018.

[19] H. A. Kefale, E. M. Getie, and K. G. Eshetie, "Optimal design of grid-connected solar photovoltaic system using selective particle swarm optimization," International Journal of Photoenergy, vol. 2021, Article ID 6632859, 9 pages, 2021.

[20] A. Badis, M. N. Mansouri, and M. H. Boujmil, "Cascade control of grid-connected PV systems using TLBO-based fractional-order PID," International Journal of Photoenergy, vol. 2019, Article ID 4325648, 17 pages, 2019.

[21] W. Tan and C. Fu, "Linear active disturbance-rejection control: analysis and tuning via IMC," IEEE Transactions on Industrial Electronics, vol. 63, no. 4, pp. 2350-2359, 2016.

[22] J. Han, "From PID to active disturbance rejection control," IEEE Transactions on Industrial Electronics, vol. 56, no. 3, pp. 900-906, 2009.

[23] J. Li, X. H. Qi, H. Wan, and Y. Xia, "Active disturbance rejection control: theoretical results summary and future researches," Control Theory \& Applications, vol. 34, no. 3, pp. 281-295, 2017.

[24] H. Yang, S. Luo, and X. D. Sun, "Research on active disturbance rejection control method of bidirectional DC-DC converter for photovoltaic energy storage," Acta Energiae Solaris Sinica, vol. 39, no. 5, pp. 1342-1350, 2018.

[25] Y. F. Cao, Y. H. Wu, Y. Q. Ye, and Y. Xiong, "Active disturbance rejection control strategy of differential feedforward for inverter," Proceedings of the CSU-EPSA, vol. 43, no. 5, pp. 136-142, 2019.

[26] A. Benrabah, D. Xu, and Z. Gao, "Active disturbance rejection control of LCL-filtered grid-connected inverter using padé approximation," IEEE Transactions on Industry Applications, vol. 54, no. 6, pp. 6179-6189, 2018.
[27] X. S. Zhou, M. Liu, and Y. J. Ma, "Improved bus voltage control of second-order LADRC wind power inverter," Proceedings of the CSU-EPSA, vol. 32, no. 6, pp. 43-50, 2020.

[28] Y. Ruan, Automatic Control System for Electric Drive, China Machine Press, Beijing, China, 2010. 